Rev.Pemo - Revista do PEMO

\title{
Relatório referente a publicação do periódico Rev.Pemo pertinente ao ano de
} 2019

Cristine Brandenburg

Universidade Federal do Ceará, Fortaleza, CE, Brasil

Karla Angélica Silva do Nascimento ii

Universidade Estadual do Ceará, Fortaleza, CE, Brasil

O referido documento tem por finalidade demonstrar o trabalho desenvolvido na Revista Práticas Educativas Memórias e Oralidades (Rev.Pemo), pertinentes aos fatos editoriais, respeitando os aspectos científicos e acadêmicos, que abrange o fluxo do período no que concerne ao ano de 2019, assim como, divulgar as principais estatísticas editoriais. A Rev.Pemo é uma revista interdisciplinar na área de humanidades, chancelada pela Editora da Universidade Estadual do Ceará (EdUECE), vinculada ao grupo de pesquisa de mesmo nome - Práticas Educativas, Memórias e Oralidades (PEMO), certificado pelo CNPQ e vinculado ao programa de Pós-Graduação da Universidade Estadual do Ceará (PPGE/UECE).

A Rev.Pemo, com seu corpo editorial, procurou disponibilizar seus arquivos na internet com a versão do OJS mais recente possível, para promover os seus artigos científicos ou produtos pedagógicos publicados de forma gratuita, disseminando assim, o conhecimento e valorizando a pesquisa.

Neste ano de 2019, o site da revista foi editado para facilitar a divulgação com as seguintes abas: Atual; Arquivos; Sobre; Notícias; Avaliadores; Indexadores/Bases/Signatários e Template. Também foi possível convidar a equipe editorial e o comitê científico da revista a partir de cartas-convite.

A equipe de avaliadores ad hoc destes primeiros números publicados foi composta por doutores(as), em sua maioria integrantes do Comitê Científico ou professores avaliadores parceiros do PEMO, referente aos anos de 2018 e 2019 . No gráfico 1, temos os avaliadores ad hoc distribuídos por região.

Rev. Pemo, Fortaleza

https://revistas.uece.br/index.php/revpemo ISSN: 2675-519X 


\section{PRÁTICAS EDUCATIVAS, MEMÓRIAS E ORALIDADES}

Rev.Pemo - Revista do PEMO

Gráfico 1 - Avaliadores ad hoc em 2019

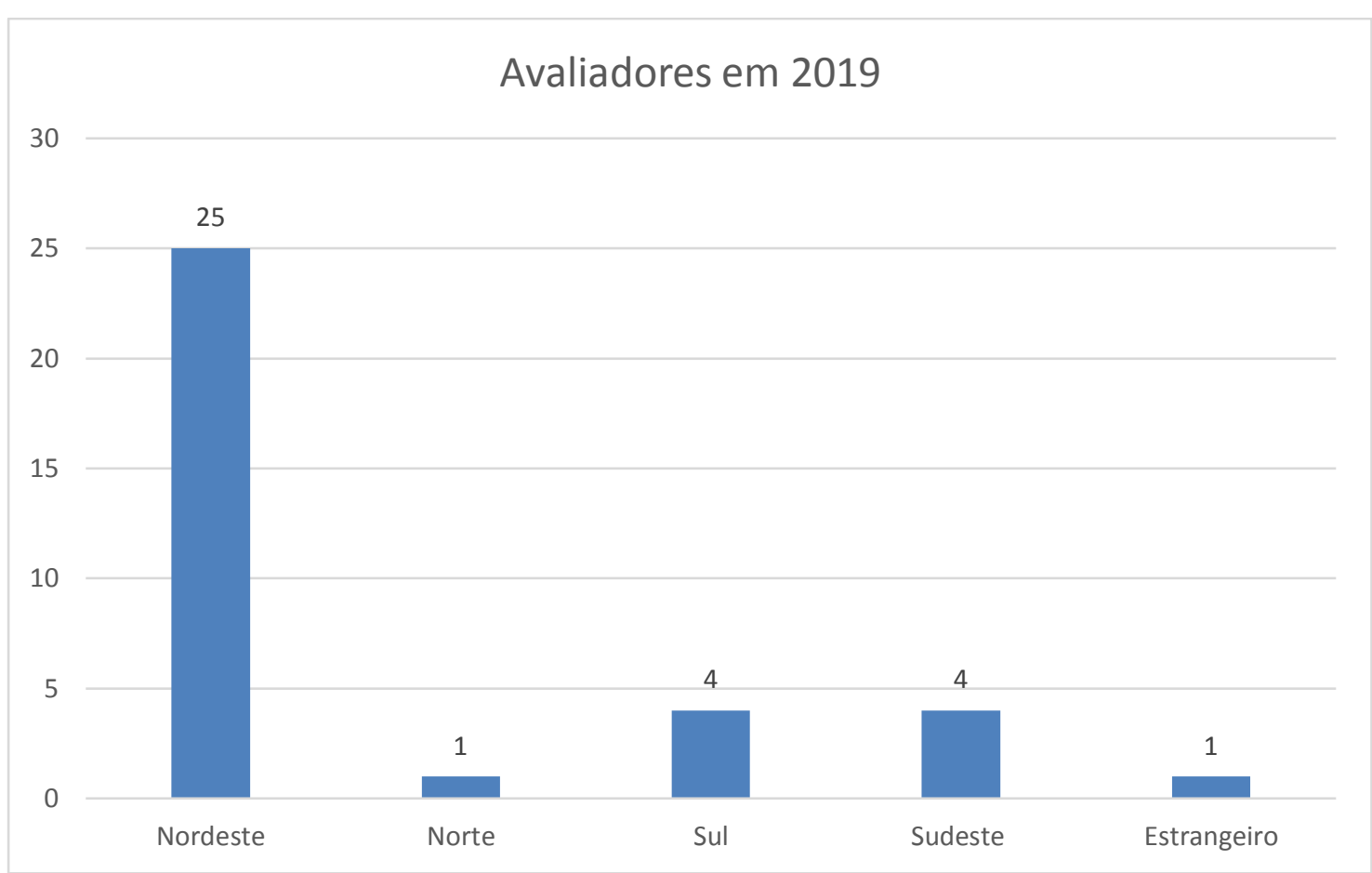

Fonte: Rev.Pemo (2019).

A Rev.Pemo, a partir do seu corpo editorial, durante os meses de janeiro a dezembro de 2019, desenvolveu um trabalho promovendo a organização funcional e o controle da produção científica da revista. Podemos destacar tais atividades como sendo:

1. Contato através de e-mail junto aos autores e pareceristas ad hoc:

a. Envio de e-mail-convite para a comunidade científica nacional e participantes do Seminário de Práticas Educativas, Memória e Oralidades promovido pelo PEMO, a fim de estimular a publicação de seus produtos científicos compartilhando e publicizando seus achados com a Rev.Pemo;

b. Seleção dos manuscritos recebidos pela Revista para verificar se atendem às normas da revista;

c. Comunicação das sugestões dos pareceristas ad hoc para os autores reformularem os textos; 


\section{PRÁTICAS EDUCATIVAS, MEMÓRIAS E ORALIDADES}

Rev.Pemo - Revista do PEMO

d. Controle dos artigos ou produtos pedagógicos: recebimento, envio para pareceristas ad hoc, reenvio aos autores;

e. Envio de cartas-convite aos pareceristas ad hoc;

f. Envio das declarações para os pareceristas ad hoc que avaliaram os artigos e produtos pedagógicos.

2. Cadastro do ISSN no lbict e do DOI de todos os artigos da revista;

a. Envio de e-mail aos autores, informando sobre a publicação do artigo, após a validação do $\mathrm{DOI}$.

3. Trabalho visando à busca de reconhecimento para a comunidade científica internacional;

a. Envio de e-mails para autores internacionais convidando a publicar suas pesquisas científicas por meio de artigos e produtos pedagógicos.

A revista manteve a política de periodicidade dos artigos publicados, sendo quadrimestral, publicando manuscritos originais na área das ciências humanas, de maneira interdisciplinar, no campo do ensino valorizando a educação e o ensino ao publicizar o conhecimento na interface das diversas licenciaturas - Pedagogia, História, Letras, Geografia, Filosofia, Ciências Sociais, Artes Visuais e afins.

A publicação dos artigos foi organizada em três números (jan./abr.; maio/ago.; set./dez.), disponíveis nos seguintes links:

$$
\begin{aligned}
& \text { v.1, n.1 (2019) - https://revistas.uece.br/index.php/revpemo/issue/view/252 } \\
& \text { v.1, n.2 (2019) - https://revistas.uece.br/index.php/revpemo/issue/view/254 } \\
& \text { v.1, n.3 (2019) - https://revistas.uece.br/index.php/revpemo/issue/view/253 }
\end{aligned}
$$




\section{PRÁTICAS EDUCATIVAS, MEMÓRIAS E ORALIDADES}

Rev.Pemo - Revista do PEMO

Gráfico 2. Fluxo de artigos em 2019

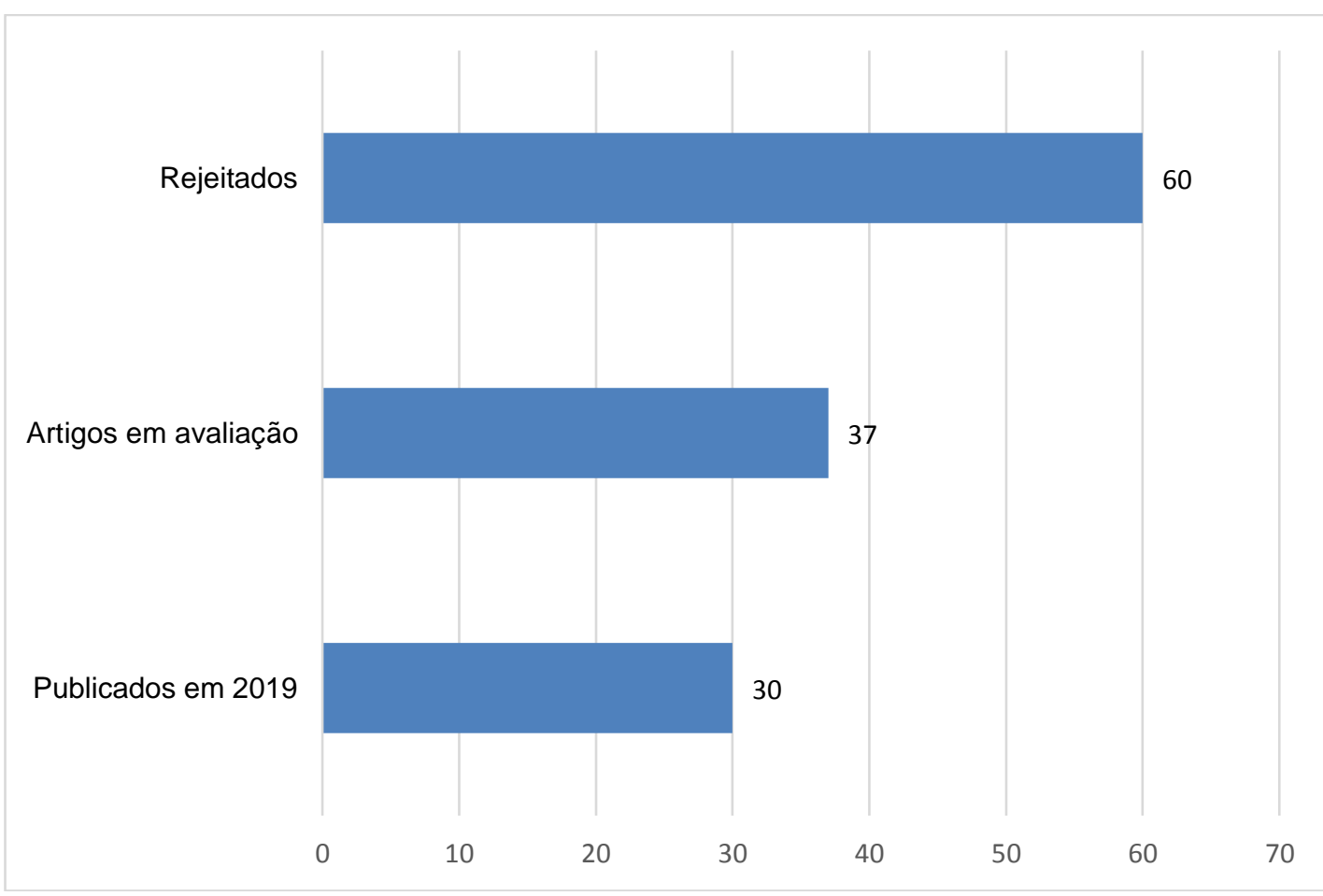

Fonte: Rev.Pemo (2019).

No decorrer do ano de 2019, através de esforço do Grupo de pesquisa Práticas Educativas, Memórias e Oralidades (PEMO), conseguimos atingir a meta almejada com a publicação de três números em 2019, com os artigos que seguem no quadro 1 - Artigos publicados v.1 n.1, em 2019; quadro 2 - Artigos publicados v.1 n.2, em 2019; quadro 3 Artigos publicados v.1 n.3, em 2019 e quadro 4 - Produtos Pedagógicos v.1 n.3, em 2019.

Quadro 1 - Artigos publicados v.1 n.1, em 2019

\begin{tabular}{|l|l|c|}
\hline \multicolumn{1}{|c|}{ Artigo } & \multicolumn{1}{c|}{ Autores } & Ano \\
\hline $\begin{array}{l}\text { Dificuldades na consulta clínica e nutricional de surdos no } \\
\text { Brasil: revisão de literatura }\end{array}$ & $\begin{array}{l}\text { NERYS, Fernanda et } \\
\text { al. }\end{array}$ & 2019 \\
\hline $\begin{array}{l}\text { Identidade e relações étnico-raciais na formação escolar } \\
\text { ARAÚJO, A. de A.; } \\
\text { SOARES, E. L. R. }\end{array}$ & 2019 \\
\hline
\end{tabular}

Rev. Pemo, Fortaleza

https://revistas.uece.br/index.php/revpemo

ISSN: 2675-519X

(c) (i) Esta obra está licenciada com uma Licença Creative Commons

Atribuição 4.0 Internacional. 


\begin{tabular}{|l|l|c|}
\hline $\begin{array}{l}\text { Trajetórias formativas de licenciandos em matemática: } \\
\text { percepções sobre constituir-se professor }\end{array}$ & $\begin{array}{l}\text { SILVA, J.; LIMA, I.; } \\
\text { PARENTES, M. D.; } \\
\text { SILVA, L. }\end{array}$ & 2019 \\
\hline $\begin{array}{l}\text { Parceria entre escola e família na formação integral da } \\
\text { criança }\end{array}$ & $\begin{array}{l}\text { COSTA, M. A.; } \\
\text { SILVA, F. M.; } \\
\text { SOUZA, D. }\end{array}$ & 2019 \\
\hline $\begin{array}{l}\text { Mestre Chitãozinho e a formação dos capoeiristas no Projeto } \\
\text { ABC do João XXIII. }\end{array}$ & $\begin{array}{l}\text { FERREIRA NETO, } \\
\text { J.; DA SILVA, R. }\end{array}$ & 2019 \\
\hline $\begin{array}{l}\text { Dialogando sobre o tema jogos populares no ensino } \\
\text { fundamental 1. }\end{array}$ & $\begin{array}{l}\text { MACIEL, J. A.; } \\
\text { MACIEL, J.; } \\
\text { MENDES, A.; } \\
\text { SILVA, J. }\end{array}$ & 2019 \\
\hline $\begin{array}{l}\text { Análise de conteúdo de "As três Marias" e a instrução } \\
\text { feminina cearense: práticas educativas, vigilância e } \\
\text { transgressão. }\end{array}$ & $\begin{array}{l}\text { SOUSA, F. G.; } \\
\text { FERNANDES, F. R. }\end{array}$ & 2019 \\
\hline $\begin{array}{l}\text { Docência no Ensino Superior: formação, iniciação e } \\
\text { desenvolvimento profissional docente. }\end{array}$ & $\begin{array}{l}\text { SANTOS, F.; } \\
\text { GIASSON, F. }\end{array}$ & 2019 \\
\hline $\begin{array}{l}\text { Memória e representação: experiências e resistências numa } \\
\text { manifestação cultural na cidade de Fortaleza }\end{array}$ & CAXILE, C. R. & 2019 \\
\hline $\begin{array}{l}\text { Formação Docente e Práxis Pedagógica narrativa de uma } \\
\text { professora }\end{array}$ & CARVALHO, S. O. & 2019 \\
\hline Fonte: Rev.Pemo (2019). & \\
\hline
\end{tabular}

Fonte: Rev.Pemo (2019).

Quadro 2 - Artigos publicados v.1 n.2, em 2019

\begin{tabular}{|l|l|c|}
\hline \multicolumn{1}{|c|}{ Artigo } & \multicolumn{1}{|c|}{ Autores } & Ano \\
\hline $\begin{array}{l}\text { Práticas reflexivas do professor reflexivo: experiências } \\
\text { metodológicas entre duas docentes do ensino superior. }\end{array}$ & $\begin{array}{l}\text { BRANDENBURG, C.; } \\
\text { PEREIRA, A.; } \\
\text { FIALHO, L. }\end{array}$ & 2019 \\
\hline $\begin{array}{l}\text { Educação profissional: um caminho para profissionalização } \\
\text { pela reconstrução da memória. }\end{array}$ & BRAUN, M. do S. & 2019 \\
\hline A profissionalidade do professor(a) de Geografia. & $\begin{array}{l}\text { COSTA, M. DO S.; } \\
\text { HOLANDA, V. C. }\end{array}$ & 2019 \\
\hline $\begin{array}{l}\text { Sextas-Feiras Complexas: Passeando por tardes de } \\
\text { discussões do pensamento complexo no Gecom (UERN). }\end{array}$ & FERREIRA, P. A. & 2019 \\
\hline
\end{tabular}

Rev. Pemo, Fortaleza

https://revistas.uece.br/index.php/revpemo

ISSN: 2675-519X

(c) (i) Esta obra está licenciada com uma Licença Creative Commons

Atribuição 4.0 Internacional. 


\begin{tabular}{|l|l|c|}
\hline $\begin{array}{l}\text { Uma perspectiva autorreflexiva sobre experiências formativas } \\
\text { docentes de dois professores iniciantes no ensino superior. }\end{array}$ & $\begin{array}{l}\text { FREIRE, V. C.; } \\
\text { MIRANDA, A. R. }\end{array}$ & 2019 \\
\hline $\begin{array}{l}\text { Saberes docentes e sua relação com a didática no processo } \\
\text { de ensino. }\end{array}$ & $\begin{array}{l}\text { FREITAS, M.; } \\
\text { OLIVEIRA, D. }\end{array}$ & 2019 \\
\hline $\begin{array}{l}\text { Temporada de Minicursos: a capacitação como meio efetivo } \\
\text { de desenvolvimento técnico e interpessoal de universitários. }\end{array}$ & $\begin{array}{l}\text { MESQUITA, P. Y.; } \\
\text { PEREIRA, J. N.; } \\
\text { SOUSA, C.; } \\
\text { MENDES, R. A.; } \\
\text { BARROSO, M. V.; } \\
\text { BERTINI, A. }\end{array}$ & 2019 \\
\hline $\begin{array}{l}\text { Itinerários de vida de Ofélia: professora gestora que } \\
\text { defendeu a escola pública na ditadura civil-militar. }\end{array}$ & $\begin{array}{l}\text { SOUSA, A. N.; } \\
\text { ASTIGARRAGA, A.; } \\
\text { FRISON, L. M. }\end{array}$ & 2019 \\
\hline $\begin{array}{l}\text { A formação inicial docente em Educação Física a partir do } \\
\text { Programa Residência Pedagógica: um relato de experiência. }\end{array}$ & $\begin{array}{l}\text { SOUSA, D.; } \\
\text { BARROSO, M. }\end{array}$ & 2019 \\
\hline $\begin{array}{l}\text { Narrativas autobiográficas de professoras da educação } \\
\text { básica: a constituição da identidade docente como processo } \\
\text { permanente. }\end{array}$ & $\begin{array}{l}\text { STASCXAK, F.; } \\
\text { SANTANA, J. }\end{array}$ & 2019 \\
\hline
\end{tabular}

Fonte: Rev.Pemo (2019).

Quadro 3 - Artigos publicados v.1 n.3, em 2019

\begin{tabular}{|l|l|c|}
\hline \multicolumn{1}{|c|}{ Artigo } & \multicolumn{1}{|c|}{ Autores } & Ano \\
\hline $\begin{array}{l}\text { Dificuldades na consulta clínica e nutricional de surdos no } \\
\text { Brasil: revisão de literatura }\end{array}$ & $\begin{array}{l}\text { NERYS, Fernanda et } \\
\text { al. }\end{array}$ & 2019 \\
\hline $\begin{array}{l}\text { Teoria da reprodução social e as desigualdades } \\
\text { educacionais. }\end{array}$ & $\begin{array}{l}\text { ALMEIDA, G.; } \\
\text { SANTOS, M. I. }\end{array}$ & 2019 \\
\hline $\begin{array}{l}\text { Narrativas de moradores do Rosado/RN: viver, contar, } \\
\text { preservar seu lugar. }\end{array}$ & $\begin{array}{l}\text { FERNANDES, S. DE; } \\
\text { AGUIAR, A. L.; } \\
\text { FERNANDES, A. }\end{array}$ & 2019 \\
\hline $\begin{array}{l}\text { Fortalecendo a cultura organizacional: a importância do } \\
\text { treinamento de novos PETianos no PET Civil UFC. }\end{array}$ & $\begin{array}{l}\text { FIALHO, B.; PRADO, } \\
\text { A. M.; OLIVEIRA, B. } \\
\text { A.; LOPES, C.; } \\
\text { ALVES, M. L.; } \\
\text { BERTINI, A. }\end{array}$ & 2019 \\
\hline
\end{tabular}

Rev. Pemo, Fortaleza

https://revistas.uece.br/index.php/revpemo

ISSN: 2675-519X

(c) (i) Esta obra está licenciada com uma Licença Creative Commons

Atribuição 4.0 Internacional. 


\begin{tabular}{|l|l|l|}
\hline A EJA no sistema penitenciário: inclusão e ressocialização. & $\begin{array}{l}\text { LOPES, M. J.; LIMA, } \\
\text { N. L.; ALMEIDA, D. }\end{array}$ & 2019 \\
\hline $\begin{array}{l}\text { Memórias e reflexões sobre a desvalorização da educação } \\
\text { física na escola brasileira }\end{array}$ & $\begin{array}{l}\text { MAIA, F. E.; } \\
\text { SANTIAGO, J.; } \\
\text { PEREIRA, J. M.; } \\
\text { ESTÁCIO, V.; LIMA, } \\
\text { R. W. }\end{array}$ & 2019 \\
\hline O tempo integral na política estadual de Educação do Ceará. & MAIA, J. E. & 2019 \\
\hline Pedagogia Empresarial e os seus Espaços de Formação. & $\begin{array}{l}\text { MENDES, M. C.; } \\
\text { OLIVEIRA, H. }\end{array}$ & 2019 \\
\hline $\begin{array}{l}\text { Exploração do conteúdo matemático função polinomial do 1o } \\
\text { grau: conhecimentos teóricos e situações práticas/cotidianas. }\end{array}$ & $\begin{array}{l}\text { NASCIMENTO, F.; } \\
\text { CASTRO, E.; LEITE, } \\
\text { L.; NASCIMENTO, R. } \\
\text { DE C.; ARAÚJO, R.; } \\
\text { LIMA, M. S. }\end{array}$ & 2019 \\
\hline $\begin{array}{l}\text { O Pibid e a formação do professor/pesquisador: na } \\
\text { UniEVANGÉLICA, na escola-campo e na intervenção } \\
\text { pedagógica dos anos iniciais do ensino fundamental. }\end{array}$ & $\begin{array}{l}\text { PAULA, T.; ABREU, } \\
\text { S. E. }\end{array}$ & 2019 \\
\hline
\end{tabular}

Fonte: Rev.Pemo (2019).

Quadro 4 - Produtos Pedagógicos v.1 n.3, em 2019

\begin{tabular}{|l|l|c|}
\hline \multicolumn{1}{|c|}{ Artigo } & \multicolumn{1}{|c|}{ Autores } & Ano \\
\hline $\begin{array}{l}\text { Produto Educacional E-book: Educação Física na Prática da } \\
\text { Educação Ambiental. }\end{array}$ & $\begin{array}{l}\text { SIMÕES NETO, J.; } \\
\text { ROCHA, A. }\end{array}$ & 2019 \\
\hline
\end{tabular}

Fonte: Rev.Pemo (2019).

O início de um periódico cientifico é sempre desafiador, e para o Grupo de Estudos Práticas Educativas, Memórias e Oralidades (PEMO) não foi diferente, pois encontramos enormes dificuldades em receber artigos de qualidade, já que a Rev.Pemo não possuía Qualis ainda e isso influenciava muito a comunidade científica brasileira na hora de escolher um periódico para submeter seus trabalhos. Ademais, o ISSN somente é fornecido após o segundo número, o que assusta os autores dos primeiros números. 


\section{PRÁTICAS EDUCATIVAS, MEMÓRIAS E ORALIDADES}

Rev.Pemo - Revista do PEMO

Apesar das dificuldades, conseguimos atingir a meta publicando 30 artigos científicos e 1 Produto Pedagógico, sendo manuscritos nacionais e internacionais, além de motivar o próprio grupo de pesquisa a desenvolver artigos científicos para divulgar as suas pesquisas acadêmicas.

\section{Referências}

ALMEIDA, G.; SANTOS, M. I. Teoria da reprodução social e as desigualdades educacionais. Práticas Educativas, Memórias e Oralidades - Rev.Pemo, v. 1, n. 3, 2019. Disponível em: https://revistas.uece.br/index.php/revpemo/article/view/3571. Acesso em: 20 jan. 2020.

ARAÚJO, Aldevane de Almeida; SOARES, Emanoel Luís Roque. Identidade e relações étnico-raciais na formação escolar. Práticas Educativas, Memórias e Oralidades -

Rev.Pemo, Fortaleza, v. 1, n. 1, p. 1-14, 2019. Disponível em: https://revistas.uece.br/index.php/revpemo/article/view/3628 Acesso em: 20 jan. 2020.

BRANDENBURG, C.; PEREIRA, A.; FIALHO, L. Práticas reflexivas do professor reflexivo: experiências metodológicas entre duas docentes do ensino superior. Práticas Educativas, Memórias e Oralidades - Rev.Pemo, v. 1, n. 2, 2019. Disponível em: https://revistas.uece.br/index.php/revpemo/article/view/3527 Acesso em: 20 jan. 2020.

BRAUN, M. do S. Educação profissional: um caminho para profissionalização pela reconstrução da memória. Práticas Educativas, Memórias e Oralidades - Rev.Pemo, v.1, n.2, 2019. Disponível em: https://revistas.uece.br/index.php/revpemo/article/view/3612 Acesso em: 20 jan. 2020.

CAXILE, C. R. Memória e representação: experiências e resistências numa manifestação cultural na cidade de Fortaleza. Práticas Educativas, Memórias e Oralidades -

Rev.Pemo, v. 1, n. 1, p. 1-18, 2019. Disponível em:

https://revistas.uece.br/index.php/revpemo/article/view/3599 Acesso em: 20 jan. 2020.

CARVALHO, S. O. Formação Docente e Práxis Pedagógica narrativa de uma professora. Práticas Educativas, Memórias e Oralidades - Rev.Pemo, v. 1, n. 1, p. 1-13, 2019. Disponível em: https://revistas.uece.br/index.php/revpemo/article/view/3602 Acesso em: 20 jan. 2020.

COSTA, M. A.; SILVA, F. M.; SOUZA, D. Parceria entre escola e família na formação integral da criança. Práticas Educativas, Memórias e Oralidades - Rev.Pemo, v. 1, n. 1, 


\section{PRÁTICAS EDUCATIVAS, MEMÓRIAS E ORALIDADES}

Rev.Pemo - Revista do PEMO

p. 1-14, 2019. Disponível em:

https://revistas.uece.br/index.php/revpemo/article/view/3476 Acesso em: 20 jan. 2020.

COSTA, M. DO S.; HOLANDA, V. C. A profissionalidade do professor(a) de Geografia. Práticas Educativas, Memórias e Oralidades - Rev.Pemo, v. 1, n. 2, 2019. Disponível em: https://revistas.uece.br/index.php/revpemo/article/view/3529 Acesso em: 20 jan. 2020.

FIALHO, B.; PRADO, A. M.; OlIVEIRA, B. A.; LOPES, C.; ALVES, M. L.; BERTINI, A. Fortalecendo a cultura organizacional: a importância do treinamento de novos PETianos no PET Civil UFC. Práticas Educativas, Memórias e Oralidades - Rev.Pemo, v. 1, n. 3, 2019. Disponível em: https://revistas.uece.br/index.php/revpemo/article/view/3639. Acesso em: 20 jan. 2020.

FERNANDES, S. DE; AGUIAR, A. L.; FERNANDES, A. Narrativas de moradores do Rosado/RN: viver, contar, preservar seu lugar. Práticas Educativas, Memórias e Oralidades - Rev.Pemo, v. 1, n. 3, 2019. Disponível em: https://revistas.uece.br/index.php/revpemo/article/view/3524. Acesso em: 20 jan. 2020.

FERREIRA NETO, J.; DA SILVA, R. Mestre Chitãozinho e a formação dos capoeiristas no Projeto ABC do João XXIII. Práticas Educativas, Memórias e Oralidades - Rev.Pemo, v. 1, n. 1, p. 1-14, 2019. Disponível em:

https://revistas.uece.br/index.php/revpemo/article/view/3518 Acesso em: 20 jan. 2020.

FERREIRA, P. A. Sextas-Feiras Complexas: Passeando por tardes de discussões do pensamento complexo no Gecom (UERN). Práticas Educativas, Memórias e Oralidades Rev.Pemo, v. 1, n. 2, 2020. Disponível em: https://revistas.uece.br/index.php/revpemo/article/view/3627 Acesso em: 20 jan. 2020.

FREIRE, V. C.; MIRANDA, A. R. Uma perspectiva autorreflexiva sobre experiências formativas docentes de dois professores iniciantes no ensino superior. Práticas Educativas, Memórias e Oralidades - Rev.Pemo, v. 1, n. 2, 2020. Disponível em: https://revistas.uece.br/index.php/revpemo/article/view/3511 Acesso em: 20 jan. 2020.

FREITAS, M.; OLIVEIRA, D. Saberes docentes e sua relação com a didática no processo de ensino. Práticas Educativas, Memórias e Oralidades - Rev.Pemo, v. 1, n. 2, 2019. Disponível em: https://revistas.uece.br/index.php/revpemo/article/view/3562 Acesso em: 20 jan. 2020.

LOPES, M. J.; LIMA, N. L.; ALMEIDA, D. A EJA no sistema penitenciário: inclusão e ressocialização. Práticas Educativas, Memórias e Oralidades - Rev.Pemo, v. 1, n. 3, 2019. Disponível em: https://revistas.uece.br/index.php/revpemo/article/view/3515. Acesso em: 20 jan. 2020. 


\title{
PRÁTICAS EDUCATIVAS, MEMÓRIAS E ORALIDADES
}

\author{
Rev.Pemo - Revista do PEMO
}

MACIEL, J. A.; MACIEL, J.; MENDES, A.; SILVA, J. Dialogando sobre o tema jogos populares no ensino fundamental 1. Práticas Educativas, Memórias e Oralidades Rev.Pemo, v. 1, n. 1, p. 1-10, 2019. Disponível em: https://revistas.uece.br/index.php/revpemo/article/view/3506 Acesso em: 20 jan. 2020.

MAIA, F. E.; SANTIAGO, J.; PEREIRA, J. M.; ESTÁCIO, V.; LIMA, R. W. Memórias e reflexões sobre a desvalorização da educação física na escola brasileira. Práticas Educativas, Memórias e Oralidades - Rev.Pemo, v. 1, n. 3, 2019. Disponível em: https://revistas.uece.br/index.php/revpemo/article/view/3580. Acesso em: 20 jan. 2020.

MAIA, J. E. O tempo integral na política estadual de Educação do Ceará. Práticas Educativas, Memórias e Oralidades - Rev.Pemo, v. 1, n. 3, 2019. Disponível em: https://revistas.uece.br/index.php/revpemo/article/view/3555. Acesso em: 20 jan. 2020.

MENDES, M. C.; OLIVEIRA, H. Pedagogia Empresarial e os seus Espaços de Formação. Práticas Educativas, Memórias e Oralidades - Rev.Pemo, v. 1, n. 3, 2019. Disponível em: https://revistas.uece.br/index.php/revpemo/article/view/3656. Acesso em: 20 jan. 2020.

MESQUITA, P. Y.; PEREIRA, J. N.; SOUSA, C.; MENDES, R. A.; BARROSO, M. V.; BERTINI, A. Temporada de Minicursos: a capacitação como meio efetivo de desenvolvimento técnico e interpessoal de universitários. Práticas Educativas, Memórias e Oralidades - Rev.Pemo, v. 1, n. 2, 2019. Disponível em: https://revistas.uece.br/index.php/revpemo/article/view/3634 Acesso em: 20 jan. 2020.

NASCIMENTO, F.; CASTRO, E.; LEITE, L.; NASCIMENTO, R. DE C.; ARAÚJO, R.; LIMA, M. S. Exploração do conteúdo matemático função polinomial do 1ํo grau: conhecimentos teóricos e situações práticas/cotidianas. Práticas Educativas, Memórias e Oralidades - Rev.Pemo, v. 1, n. 3, 2019. Disponível em: https://revistas.uece.br/index.php/revpemo/article/view/3579. Acesso em: 20 jan. 2020.

NERYS, Fernanda et al. Dificuldades na consulta clínica e nutricional de surdos no Brasil: revisão de literatura. Práticas Educativas, Memórias e Oralidades - Rev.Pemo, Fortaleza, v. 1, n. 1, p. 1-15, 2019. Disponível em:

https://revistas.uece.br/index.php/revpemo/article/view/3605 Acesso em: 20 jan. 2020.

PAULA, T.; ABREU, S. E. O Pibid e a formação do professor/pesquisador: na UniEVANGÉLICA, na escola-campo e na intervenção pedagógica dos anos iniciais do ensino fundamental. Práticas Educativas, Memórias e Oralidades - Rev.Pemo, v. 1, n. 3, 2019. Disponível em: https://revistas.uece.br/index.php/revpemo/article/view/3641. Acesso em: 20 jan. 2020.

SANTOS, F.; GIASSON, F. Docência no Ensino Superior: formação, iniciação e desenvolvimento profissional docente. Práticas Educativas, Memórias e Oralidades - 


\section{PRÁTICAS EDUCATIVAS, MEMÓRIAS E ORALIDADES}

Rev.Pemo - Revista do PEMO

Rev.Pemo, v. 1, n. 1, p. 1-12, 2019. Disponível em:

https://revistas.uece.br/index.php/revpemo/article/view/3543 Acesso em: 20 jan. 2020.

SILVA, J.; LIMA, I.; PARENTES, M. D.; SILVA, L. Trajetórias formativas de licenciandos em matemática: percepções sobre constituir-se professor. Práticas Educativas, Memórias e Oralidades - Rev.Pemo, v. 1, n. 1, p. 1-14, 2019. Disponível em: https://revistas.uece.br/index.php/revpemo/article/view/3478 Acesso em: 20 jan. 2020.

SIMÕES NETO, J.; ROCHA, A. Produto Educacional E-book: Educação Física na Prática da Educação Ambiental. Práticas Educativas, Memórias e Oralidades - Rev.Pemo, v. 1, n. 3, 2019. Disponível em: https://revistas.uece.br/index.php/revpemo/article/view/3566. Acesso em: 20 jan. 2020.

SOUSA, A. N.; ASTIGARRAGA, A.; FRISON, L. M. Itinerários de vida de Ofélia: professora gestora que defendeu a escola pública na ditadura civil-militar.

Práticas Educativas, Memórias e Oralidades - Rev.Pemo, v. 1, n. 2, 2019. Disponível em: https://revistas.uece.br/index.php/revpemo/article/view/3648 Acesso em: 20 jan. 2020.

SOUSA, D.; BARROSO, M. A formação inicial docente em Educação Física a partir do Programa Residência Pedagógica: um relato de experiência. Práticas Educativas, Memórias e Oralidades - Rev.Pemo, v. 1, n. 2, 2019. Disponível em: https://revistas.uece.br/index.php/revpemo/article/view/3570 Acesso em: 20 jan. 2020.

SOUSA, F. G.; FERNANDES, F. R. Análise de conteúdo de "As três Marias" e a instrução feminina cearense: práticas educativas, vigilância e transgressão. Práticas Educativas, Memórias e Oralidades - Rev.Pemo, v. 1, n. 1, p. 1-17, 2019. Disponível em: https://revistas.uece.br/index.php/revpemo/article/view/3484 Acesso em: 20 jan. 2020.

STASCXAK, F.; SANTANA, J. Narrativas autobiográficas de professoras da educação básica: a constituição da identidade docente como processo permanente. Práticas Educativas, Memórias e Oralidades - Rev.Pemo, v. 1, n. 2, 2019. Disponível em: https://revistas.uece.br/index.php/revpemo/article/view/3512 Acesso em: 20 jan. 2020.

\footnotetext{
' Cristine Brandenburg, ORCID: https://orcid.org/0000-0002-9296-6034

Universidade Federal do Ceará, Programa de Pós-Graduação em Educação Brasileira Doutora pelo Programa de Pós-Graduação em Educação Brasileira pela Universidade Federal do Ceará, Bolsista CNPq (2019). Vice-Líder do grupo de pesquisa Práticas Educativas Memórias e Oralidades (PEMO). Editora da Revista Práticas Educativas, Memórias e Oralidades - Rev.Pemo. Contribuição de autoria: revisou a metodologia e a coleta de dados; contribuiu com os resultados. Lattes: http://lattes.cnpq.br/2190827089014447

E-mail: crisfisio13@gmail.com
}

Rev. Pemo, Fortaleza

https://revistas.uece.br/index.php/revpemo ISSN: 2675-519X

(c) (i) Esta obra está licenciada com uma Licença Creative Commons Atribuição 4.0 Internacional. 


\section{PRÁTICAS EDUCATIVAS, MEMÓRIAS E ORALIDADES}

Rev.Pemo - Revista do PEMO

ii Karla Angélica Silva do Nascimento, ORCID: https://orcid.org/0000-0001-6103-2397

Universidade Estadual do Ceará, Programa de Pós-Graduação em Educação

Pós-doutoranda em Educação pelo Programa de Pós-Graduação em Educação da Universidade

Estadual do Ceará. Doutora em Educação Brasileira pela Universidade Federal do Ceará, Bolsista PNPD/Capes. Secretária executiva da Revista Educação \& Formação.

Contribuição de autoria: realizou a escrita, a metodologia, a coleta de dados, copilou os resultados e iniciou as discussões.

Lattes: http://lattes.cnpq.br/5267121220942302

E-mail: karla.asn@gmail.com

Rev. Pemo, Fortaleza

https://revistas.uece.br/index.php/revpemo

ISSN: 2675-519X

(c) (i) Esta obra está licenciada com uma Licença Creative Commons

Atribuição 4.0 Internacional. 